\title{
Hardened AISI 4140 Steel Subjected to Hydrogen
}

Noé López Perrusquia ${ }^{1}$, Marco Antonio Doñu Ruiz ${ }^{1}$, Victor Hugo Olmos Domínguez ${ }^{2}$, Jorge Victor Cortes Suarez ${ }^{3}$, Jose Luis Velázquez Mendoza ${ }^{3}$ and David Sanchez Huitron ${ }^{4}$

${ }^{1}$ Universidad Politecnica del Valle de México, Tultitlan, Distrito Federal, Mexico, ${ }^{2}$ Universidad Tecnológica de México Campus Atizapán, ESTADO DE MEXICO, Distrito Federal, Mexico, ${ }^{3}$ Universidad AutónomaMetropolitana Unidad Azcapotzalco, México, Distrito Federal, Mexico, ${ }^{4}$ Universidad Politécnica del Valle de México, Tultitlan, Distrito Federal, Mexico

The nuclear industry assigns millions of dollars each year to the repair or replacement of materials that fail due to the degradation of mechanical properties caused by the effect of hydrogen [1-2]. Hydrogen embrittlement is one of the causes of failure of metallic materials in service, because of contact with hydrogen [3-4]. the engineering of manufacturing maritime, naval, geothermal, hydrocarbon transport, biofuel storage, automotive, metalworking, foundry, petrochemical and other areas have the problem that materials suffer alterations in the mechanical properties by the interaction with hydrogen; for this reason the demand in ferrous materials resistant the interaction with hydrogen [5-6].This work studies the effect of the microstructures obtained by different heat treatments proposed on a mechanical steel AISI 4140 steel exposed to hydrogen permeation. In addition, the evaluation of the mechanical property of maximum bending strength at fracture on specimens heat-treated with hydrogen permeation and without hydrogen permeation. It was used AISI 4140 steel with chemical composition $0.40 \% \mathrm{C}, 0.80 \% \mathrm{Mn}, 0.25 \% \mathrm{Si}, 1.00 \%$ $\mathrm{Cr}, 0.20 \% \mathrm{Mo}, 0.04 \% \mathrm{~S}$ and $0.035 \% \mathrm{P}$; for machining specimens of three-point bending, with dimensions $52.00 \mathrm{~mm}$ long, $12.00 \mathrm{~mm}$ wide, $5.5 \mathrm{~mm}$ thick and with a V-type notch at 45 degrees. After, the specimens were rectified to eliminate the rough surface by machining process. First, a heat treatment with a temperature of $630{ }^{\circ} \mathrm{C}$ for $2 \mathrm{~h}$, for removing residual stresses from the machined specimens. Next, the specimens were subjected to austenitized treatment at a temperature of $825^{\circ} \mathrm{C}$ for $1 \mathrm{~h}$ and oil quenching at ambient temperature; followed by quenching for $2 \mathrm{~h}$ at a temperature of $200^{\circ} \mathrm{C}$; with air cooling (ATQ) using a liderberg muffle. The specimens treated with ATQ were exposed to permeation for $24 \mathrm{~h}$ according to ASTM G148-97 [7]. For microstructural revelation, using metallographic processing and chemical etching with reactivated nital at $2 \%$ for 20 seconds on specimens treated with ATQ; without and with hydrogen permeation by scanning electron microscopy equipment using a JEOL JSM-6063 LA. Hardness was evaluated in HRC according to ASTM E18 [8] on specimens treated with ATQ; without hydrogen permeation; using a Durometer Mitutoyo. Specimens treated with ATQ; without and with hydrogen permeation were exposed to bending test according to ASTM E399 [9]; using a universal mechanical testing machine; Instron model 8502, with capacity of $200 \mathrm{kN}$ and advance speed to $0.102 \mathrm{~mm} / \mathrm{min}$. In addition, the fracture surfaces of the specimens treated with ATQ; without and with hydrogen permeation were analyzed using a scanning electron microscope using a JEOL JSM-6063 LA.Zafra et. al. and Hafeez et. al. [10-11]; exhibit the effect of quenching and tempering heat treatments on steels, showing the benefits of the microstructure and mechanical properties obtained for possible applications in the industries of hydrogen, naval, maritime and aerospace. Also different studies report on the types of microstructure and phases that retard hydrogen diffusion [12-13]. For this reason, Figure 1a shows the result of microstructure of martensite tempered with a hardness of $55.4 \mathrm{HRC}$ on specimens treated with ATQ without hydrogen permeation. Figure 1b, also shows microstructure of martensite with non-metallic particles (manganese sulfides) for the ATQ treated specimens without hydrogen permeation. The martensite obtained shows lath-type orientations, caused by the carbon movement by the temperature treatment proposed in this study. The hardness obtained on the specimens heat treated with ATQ can be attributed to quenching temperature. Figure $1 \mathrm{c}$ and $1 \mathrm{~d}$; show the generation of defects caused to specimens 
treated with ATQ exposed to hydrogen permeation, showing the orientation of the cracks in the martensite structure and cracks in different directions converging at a same point. The results of bending test, without hydrogen permeation on specimens treated with ATQ show the values of bending to fracture of $9703.0 \mathrm{~N}$, toughness of $6.75 \mathrm{~J}$ and maximum stress in the notch of $5155 \mathrm{MPa}$. For specimens treated with ATQ exposed to hydrogen permeation, show bending at fracture values of $3128.9 \mathrm{~N}$, toughness of $1.21 \mathrm{~J}$ and maximum stress at notch of $1662.8 \mathrm{MPa}$. The reduction in values of fracture bending, toughness and maximum stress in the notch on AQT-treated specimens exposed to hydrogen permeation can be attributed by the presence of martensite that generates dislocations as hydrogen traps, and the non-metallic inclusions of manganese sulfide type are volume defects acting as hydrogen traps, slowing the diffusion of hydrogen to the outside. This heat treatment ATQ produced a martensite, creating a higher concentration of traps for hydrogen entrapment and it can retard hydrogen diffusion.Figure 2a shows the aspects of the specimens treated with AQT, without hydrogen loading the fracture surface evidences the different mechanisms of intergranular fracture, transgranular and brittle zone transition, as well as shear lips in the "A" zone, also details of cleavage zones and intergranular separations are observed. Figure $2 b$ shows the fracture surface of the specimens with AQT with hydrogen, the transgranular and intergranular fracture mechanism is observed, in zone "A" it also shows a grain type separated from the adjacent grain boundaries of the crystal structure, local transgranular separations are also observed.
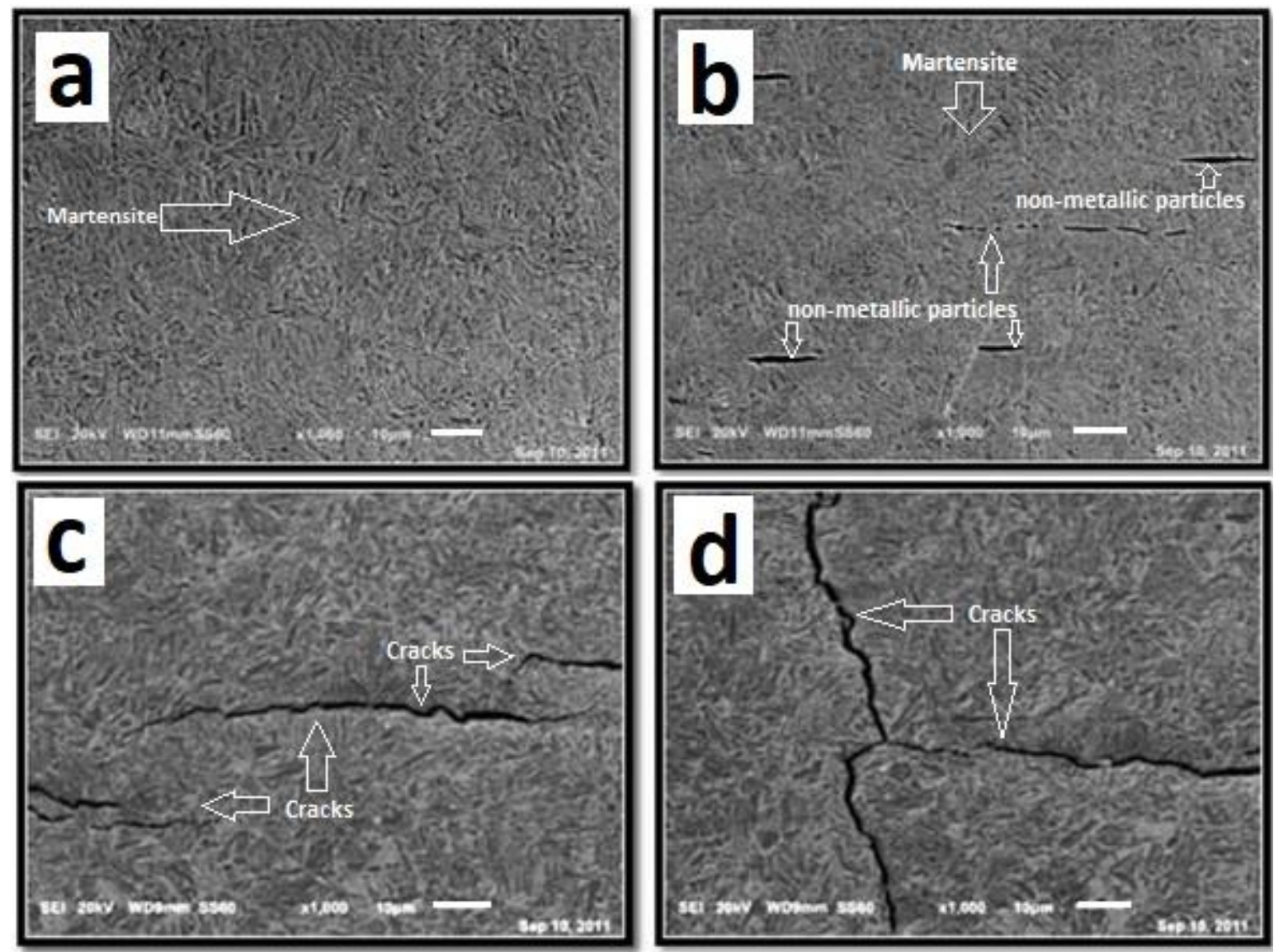

Figure 1. Figure.1 SEM micrographs of heat-treated specimens: (a) ATQ without hydrogen charging shows Martensite; (b) ATQ without hydrogen charging shows Martensite with nonmetallic particles; (c) and (b) ATQ with hydrogen charging shows Cracks on Martensite. 

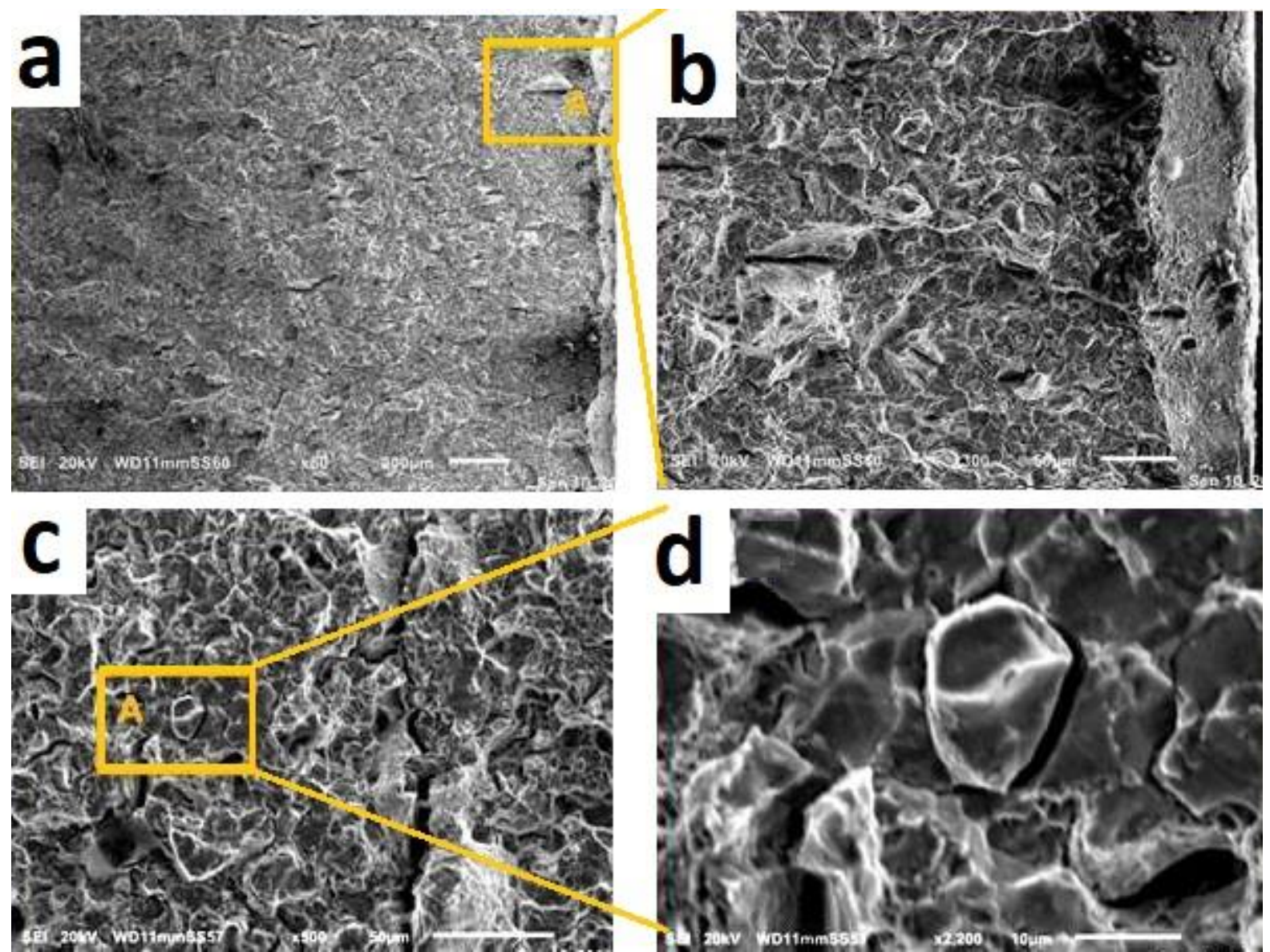

Figure 2. Figure 2. Fracture types of the treated specimens: (a) ATQ without hydrogen charging; (b) ATQ without hydrogen charging in zone "A"; (c) ATQ without hydrogen charging and (d) ATQ with hydrogen charging in zone "A"

References

[1]R.P. Gangloff, B.P. Somerday,Gaseous Hydrogen Embrittlement of Materials in Energy Technologies, Volume 1: The Problem, its Charaterization and Effects on Particular Alloy ClassesWoodhead Publishing Limited, Cambridge, UK (2012)

[2]H. Fritzsche, F. Klose, C. Rehm, Z. Tun. M. Wolff, and B. Hjörvarsson, Neutron Reflectometry in "Neutron Scattering and Other Nuclear Techniques for Hydrogen in Materials", H. Fritzsche, J. Huot, D. Fruchart (Editors), Springer (2016).

[3]J.H Chuang. et. al. Fatig. 20, (7) (1998), P.531-536. doi.org/10.1016/S0142-1123(98)00019-X.

[4]Sandeep Kumar Dwivedi. et. al. Inter. Jour, Hydr. Ener. 43 (46) (2018) p. 21603-21616. doi.org/10.1016/j.ijhydene.2018.09.201.

[5]N. López Perrusquia. et. al. Surf. Coat. Technol. 377 (2019), p. 124880. doi.org/10.1016/j.surfcoat.2019.08.009

[6]López Velázquez I. et. al. Microscopy and Microanalysis, 25(S2) (2019), p. 1602-1603. doi:10.1017/S1431927619008742

[7]ASTM E399 - 20a Standard Test Method for Linear-Elastic Plane-Strain Fracture Toughness of Metallic Material

[8]J.P.D. Carvalho. et. al. Int. J. Hydrog. Energy 42 (2017), p. 681-688. doi.org/10.1016/j.ijhydene.2016.10.127. 
[9]Annual book of ASTM standards. ASTM E18 standard test method for Rockwell Hardness and Rockwell Superficial Hardness of Metallic Materials, Vol. 03.01. ASTM Int, PA; 2005.

[10]Hafeez, M.A. et. al. Microstruct. Anal. 8 (2019), p. 479-487. doi.org/10.1007/s13632-019-00556-x [11]A.Zafra. et. al. Journal of Pressure Vessels and Piping. 171 (2019), p. 34-50. doi.org/10.1016/j.ijpvp.2019.01.020

[12]Chiara Colombo. et. al. TheorApplFractMec. $110 \quad$ (2020), p.102810. doi.org/10.1016/j.tafmec.2020.102810

[13] Zheng, L. et. al. Met. Mater. Int. 19 (2013), p.1373-1376 . doi.org/10.1007/s12540-013-6034-7 